\title{
Apontamentos para uma história comparada do esporte: um modelo heurístico
}

CDD. 20.ed. 796.05

796.08

Victor Andrade de MELO*

\section{Resumo}

Ao analisar o recente crescimento do número de investigações históricas que têm como objeto as práticas corporais institucionalizadas, MELO (2007a), mesmo reconhecendo a importância desses esforços, demonstra preocupação com a fragmentação e o não estabelecimento de iniciativas de maior alcance. Para esse autor, uma possível saída estaria na utilização do método da História Comparada, uma contribuição para a busca de sinteses históricas mais aprofundadas. Partindo dessas compreensões, esse artigo tem por objetivo apresentar um modelo heuristico cujo intuito é constituir-se em ferramenta para analisar/interpretar a trajetória conceitual moderna do fenômeno esportivo. Construído basicamente a partir do próprio percurso histórico do esporte, cremos que pode se constituir em um bom instrumento não só para o desenvolvimento de estudos locais, como também, talvez ainda mais, de investigações comparadas.

UnItermos: História do esporte; Sociologia do esporte; Metodologia da história.

\section{Introdução}

Ao analisar o recente crescimento do número de investigações históricas que têm como objeto as práticas corporais institucionalizadas ${ }^{1}$, Melo (2007a), mesmo reconhecendo a importância desses esforços, demonstra preocupação com a fragmentação e o não estabelecimento de iniciativas de maior alcance:

Não estaríamos perdendo a visão do "todo" em

função da fragmentação das abordagens? Como ampliar nossa visão acerca da realidade nacional sem crer que essa é simplesmente o resultado da soma dos entendimentos locais? Como construir hipóteses mais amplas, pensando, por exemplo, no cenário latino-americano, contexto no qual estamos inseridos não somente por questôes geográficas, mas também por relaçōes históricas, culturais e políticas? Como fazer dialogar a produção brasileira com o que tem sido produzido internacionalmente? (p.4).

Para esse autor, uma possível saída estaria na utilização do método da História Comparada: sem que seja compreendido como um remédio para todos os males, suas propostas, mesmo que com ressalvas, contribuiriam para a busca de sínteses históricas mais aprofundadas. Além disso: "O método comparativo pode ainda nos abrir oportunidades de passarmos de nossos importantes estudos locais para apreensōes mais amplas, abrindo diálogo do local e do nacional com o global" (Melo, 2007a, p.32).

Partindo dessas compreensões, esse artigo tem por objetivo apresentar um modelo heurístico ${ }^{2}$ cujo intuito é constituir-se em ferramenta para analisar/interpretar a trajetória conceitual moderna do fenômeno esportivo. Construído basicamente a partir do próprio percurso histórico do esporte, cremos que pode se constituir em um bom instrumento não só para o desenvolvimento de estudos locais, como também, talvez ainda mais, para o entabular de investigações comparadas.

\section{Apontamentos iniciais: um breve percurso pela história do "sport"}

Primeira a aceitar o princípio da competição na vida econômica, primeira a introduzi-lo no recrutamento de sua burocracia, a Inglaterra também fora a primeira a idealizá-lo no esporte, enobrecendo-o 
com as noçôes de espírito esportivo e fair play, transformando-o numa convenção social. Outras naçôes modernas tinham que seguir o exemplo ou enfrentar graves riscos (WEBER, 1988, p.282).

"Todos os povos têm seus jogos, mas nenhuma das grandes nações modernas os construiu tanto como uma regra de vida e um código nacional”. Esse foi o veredicto de um visitante alemão sobre a Inglaterra dos anos 1920 [...]. "É a natural evolução do espírito de jogo", ele continua, "que deu à personalidade inglesa sua mais interessante feição e desde o ponto de vista político, cultural e amplamente humano, seu mais importante aspecto (HoLT, 1989, p.1).

A palavra "sport" parece ter sido pela primeira vez registrada na Inglaterra do século XV, originária do francês antigo 3 "disport", que curiosamente tinha como origem o latim "deportare", que significava "enviar para fora" (daí é também originada a palavra deportar). Apreendida como "levar para longe dos negócios", na França significava "diversão", mas também era usada na acepção de prazer; na grande ilha acabou assumindo um sentido aproximado, de divertimento e até mesmo de travessura. A ideia de competição não era ainda explícita.

No século XVI, ela começa a adquirir o sentido de “jogo que envolve atividade física”, embora tivesse majoritariamente mantido sua acepção original, tanto assim que era usada para designar a representação teatral e a performance musical ${ }^{4}$, algumas vezes até mesmo a relação sexual (WELSCH, 2001). Paulatinamente deixa de significar só uma ação e confunde-se com o próprio objeto, também sendo relacionada a jogos de azar.

No século XVIII, já se identifica o uso de "sportsman", para designar o envolvido constantemente com a prática, e "sportsmanship", para designar uma natureza de envolvimento. Percebe-se que nesse instante o conceito se torna mais preciso, mais restrito (no que se refere à natureza das atividades, embora ampliado no sentido de expressar um número maior de dimensōes) e já aponta para o que será configurado no século seguinte. A ideia de competição torna-se mais clara, mesmo que não totalmente preponderante. $\mathrm{O}$ que estava por trás dessas mudanças?

Certamente há uma forte relação com o cenário sociocultural inglês, notadamente com os desdobramentos da Revolução Gloriosa, processo que exponenciou a influência dos interesses fundiários e demarcou as condiçōes tanto para o delineamento de uma aristocracia diferenciada quanto para a emergência da "gentry" como uma burguesia que adotou um estilo de vida que combinava o rural e o urbano. Ao mesmo tempo se fortalece um estrato social intermediário que gozava de bom grau de liberdade para suas ações e uma elite intelectual que defendia direitos civis, reformas sociais e inclusão social das classes médias.

Os desdobramentos desse processo colocariam a Inglaterra na ponta-de-lança do progresso nos séculos XVIII e XIX. Observa-se a gestação de novos estilos de sociabilidade relacionados a uma nova conformação do espaço urbano, ao fortalecimento de um mercado consumidor, à valorização da iniciativa e da propriedade privadas, do acúmulo de riquezas, da busca de instrução e conhecimento.

Nesse cenário, no decorrer do século XVIII, o esporte progressivamente estruturou-se, marcado pela ideia de racionalidade, bem como inserido em um mercado de entretenimento em gestação 5 . Nos anos iniciais da centúria, o termo era muito usado para designar as atividades de diversão que eram realizadas no campo, relacionadas a animais: especialmente as corridas de cavalo, a caça e a pesca ${ }^{6}$. A prática se configurou claramente como um elemento de status e distinção, não acessível a todos, nem mesmo a uma parte das classes médias. Como lembra Roy PORTER (2001):

As classes possidentes da época georgiana e do início da era vitoriana gozavam o lazer nas suas próprias terras, simbolicamente, pelo exercício de seus direitos de caça, defendidos dos intrusos, de uma maneira quase religiosa por uma legislação cada vez mais severa. Através das leis da caça que previam prisão, expulsão ou mesmo a morte daqueles que a fome impelisse à caça furtiva, a majestade do Parlamento protegeu os prazeres exclusivos de uma elite para a qual a caça era a atividade predileta (p.23).

$\mathrm{Na}$ verdade, esse era o perfil da "gentry": ainda que uma nova formação cultural estivesse em marcha, em grande parte persistia um estilo de vida aristocrático. Como lembra HoвsBawm (2009): A triunfante supremacia da Grã-Bretanha fez do nobre inglês o padrão da cultura, ou melhor, da incultura aristocrática internacional, pois os interesses do dandy - bem barbeado, impassível e refulgente - deviam ser limitados a cavalos, cães, carruagens, pugilistas profissionais, caça, jogos, diversōes de cavalheiros e sua própria pessoa (p.374).

De qualquer forma, esse novo formato de prática, cujas raízes já podem ser encontradas nos anos finais do século XVII, inaugura um novo sentido de velocidade que no século seguinte seria exponenciado, substituindo na ocasião as antigas atividades 
mais diretamente relacionadas às armas: "uma vez que a ordem militar se tornou uma ordem entre as outras, as implicações simbólicas dos jogos marciais derivaram ou desapareceram. Os torneios e seus longínquos derivados deram lugar à caça e às corridas de cavalos" (Vigarello, 2008, p.395).

Também eram denominadas "sports" algumas atividades de maior popularidade entre outras camadas sociais, entre elas as brigas de animais e as touradas. $\mathrm{O}$ pintor Henry Thomas Alken chegou a escrever, em 1825, o livro Os esportes nacionais da Grä-Gretanha, fartamente ilustrado, no qual comenta e critica essas formas de diversão ${ }^{7}$.

As lutas já eram populares. A princípio, não havia muitas regras, árbitros, limite de tempo, proteção para os lutadores, instalação para o público e mesmo uma técnica única, misturando-se elementos do que, no futuro, comporiam estilos diversos. A vitória era consagrada quando um dos participantes desistisse, desmaiasse ou, o mais trágico, viesse a morrer.

No século XVIII, já as vemos mais organizadas. Alguns "empresários" melhor estruturaram a prática de acordo com o novo espírito comercial; eram claros os interesses financeiros. Logo surgem a necessidade de estabelecimento de normas, o desejo de registrar o feito dos campeões, os primeiros profissionais responsáveis pela preparação de lutadores, um calendário de combates.

Um dos primeiros nomes de relevância dessa fase é o de James Figg, hoje reconhecido como o primeiro campeão inglês (1719), um dos responsáveis pela popularização do boxe, tanto por ter aberto uma escola quanto por viajar constantemente pelo país, realizando apresentaçóes.

É de se destacar a relação de Figg com William Hogarth, um dos grandes artistas ingleses do século XVIII, uma das chaves para entender a grande celebridade nacional obtida pelo boxeador. Hogarth foi o responsável pelo cartão pessoal (nele se lia "mestre da nobre ciência da defesa”) e por um famoso retrato do lutador (sem data precisa $)^{8}$, no qual podemos vê-lo não em uma disputa, mas sim dando aulas para um público que assistia atento; um anúncio de suas "atividades docentes".

$\mathrm{O}$ pugilista esteve presente em outras obras de Hogarth, entre as quais Southwark Fair and a Rake's progress $(1735)^{9}$. Concluída um ano após a morte do boxeador, pode-se ver um panorama de alguns tipos que compunham a cena londrina naquele momento, quase um retrato de um estrato social intermediário que emergia, nesse caso relacionado à nova dinâmica de divertimentos que se delineava: um poeta, um cabeleireiro, um alfaiate, um músico, um mestre de esgrima, um mestre de dança, um jardineiro, um guarda-costas, um caçador e um jóquei, além de Figg.

Desse momento inicial, devemos ainda lembrar de Jack Broughton, campeão contumaz e responsável por sistematizar um conjunto de regras que contribuiu para estabilizar a prática. Ele também foi representado por Hogarth; ele e Figg, aliás, foram ainda retratados pelo importante gravurista John Faber.

Nesse momento podemos também identificar os primórdios dos esportes náuticos. $\mathrm{O}$ uso dos iates para atividades de diversão, na Inglaterra, remonta ao século XVII, uma influência holandesa supostamente incentivada por Charles II, que retornara do exílio naquele país. Inicialmente, o Tâmisa era o local preferido para a navegação. A prática logo se deslocou para o Porto de Harbour, na Irlanda, graças à ação de um correligionário do rei, o Conde de Inchiquin. Em 1720, é fundado aquele que é tido como o mais antigo clube de iatismo do mundo, o Water Club of the Harbour of Cork, que depois se transformou no Royal Cork Yacht Club.

$\mathrm{O}$ iatismo sempre se estabeleceu como uma atividade mais restrita, somente disponível para os mais ricos. Já com o remo, o processo foi sensivelmente distinto: era inicialmente mais praticado por membros das camadas populares, que obtinham certo renome quando vitoriosos.

O aumento da relação de Londres com o Tâmisa está relacionado ao processo de industrialização, urbanização e melhor estruturação do comércio. De um lado, as margens e as águas, paulatinamente, serão ocupadas pelos novos entretenimentos; de outro, o aumento da poluiçãao e da circulação de gente e mercadorias trará reflexos negativos, não poucas vezes ocasionando degradação.

Entre as festividades náuticas realizadas no rio, a Doggett's Coat and Badge foi a pioneira corrida de barcos formalmente organizada (a primeira edição ocorreu em 1715), uma iniciativa de Thomas Doggett, um ator irlandês que fez grande sucesso em Londres e tornou-se um dos diretores do Drury Lane Theatre Royal. O evento, originalmente, era tanto uma forma de agradecer aos marinheiros ${ }^{10}$, que o tinham salvo de um naufrágio, quanto uma homenagem a George I, por ocasiāo do primeiro aniversário de sua ascensão ao trono.

O modelo de organização e os símbolos utilizados expressavam a celebração de um novo tempo, supostamente de maior liberdade, ideia relacionada às mudanças no sistema político inglês, com a instituição de um gabinete sob a liderança de um primeiro-ministro ${ }^{11}$.

Enfim, sobre esse momento dos esportes, bem resumem Vigarello e Holt (2008): 
Os antigos esportes não eram codificados. Faziam parte da cultura aldeã tradicional ou então eram praticados por ocasião de acontecimentos excepcionais. Ao mesmo tempo, autorizavam os divertimentos públicos, as apostas e o lucro. Não se tinha necessidade de organizar competiçôes regulares. Não existia classe especial de esportistas que tivessem recebido uma formação para jogos e fossem obrigados a manter a forma. Não havia tampouco rede nacional ou local de transporte, nem verdadeira imprensa esportiva. Reinava um fascínio geral pelos desempenhos extremos, mas não havia nenhum acordo estabelecido sobre o que devia ser o corpo atlético ideal (p.427).

O remo, no decorrer do século XIX, será apreendido e sistematizado no âmbito das escolas britânicas. Na verdade, clubes destinados à prática desde 1790 já existiam no Eton College e na Westminter School. Na Universidade de Oxford, existe desde 1815, enquanto em Cambridge, desde 1827; em 1829 , houve a primeira edição da tradicional disputa entre essas duas instituiçôes.

Nesse momento, algumas práticas populares, notadamente as brigas de animais, começaram a ser perseguidas, ações diretamente relacionadas à configuração dos novos sentidos e significados da modernidade, ligadas aos interesses da consolidação do capitalismo, à nova dinâmica do espaço urbano (a cidade industrial), à ideia de autocontrole tão propalada pelo espírito vitoriano:

Nos séculos XVIII eXIX, foram lançadas campanhas pelo controle ou supressão dos jogos plebeus, lutas de ursos e de cães ou corridas de touro em prol de uma "reforma da cultura". A despeito da popularidade persistente de certos divertimentos em todas as categorias sociais, como corridas hípicas ou combates de boxe profissional, muitos sinais mostram que no início da era vitoriana as actividades de lazer começam a obedecer a uma diferenciação social cada vez mais nítida (PORTER, 2001, p.24).

Um novo conceito de "sport" está sendo delineado. É no início do século XIX que surge o adjetivo "sporting"; no desdobramento, aparecerão tanto vocábulos que ligam o fenômeno a um estilo de vida ("sportswear", "sporting car", por exemplo) quanto palavras que designam melhor as peculiaridades da prática (exemplos: "crack", "ace", "corner" etc.). A melhor configuração de uma terminologia própria, nesse caso, é um indício do delineamento de uma nova construção conceitual, ainda que fazendo uso da mesma palavra.

Conforma-se um conceito moderno de esporte, marcado pelas novas dimensões culturais relacionadas às classes médias, uma prática que, em linhas gerais, atende a algumas características.

- Organiza-se em entidades representativas (locais, nacionais e internacionais); o club, que se delineara nos "coffee shops" e "public houses" ingleses do século XVIII, será a unidade fundamental de estruturação. A palavra surgiu no século XIII e é somente no século XVII que ganhou a acepção de associação de pessoas para um fim em comum. Os clubes se estruturaram como bases da sociedade civil, uma forma de conformar novas identidades (de categoria, de classe, nacional, regional, local). Como lembra SOARES (2007), essas agremiaçōes:

[...] se tornaram os microcosmos de uma rica experiência cultural que, excluindo os excessos de zombaria, do deboche, da obscenidade, refletiu algumas das principais características do movimento ilustrado na Inglaterra, sobretudo naquilo que se relacionava à disseminação de um ideal de liberdade, tolerância, polidez, civilidade e refinamento social (p.185).

- Possui um calendário próprio, já não mais seguindo estritamente outros tempos sociais ou rituais.

- Envolve um corpo técnico especializado cada vez maior (treinadores, preparadores físicos, dirigentes, gestores, psicólogos, médicos, entre muitos outros).

- Gera um mercado ao seu redor, que extrapola até mesmo o que a princípio poderia ser considerado específico da prática esportiva ${ }^{12}$.

Embora não exclusivamente, em boa medida o movimento de sistematização do esporte moderno parte das "public schools"13 inglesas ${ }^{14}$, que, desde os anos 1820, estiveram cada vez mais influenciadas pela ideia de "cristianismo muscular", proposta que Thomas Arnold liderava a partir da escola de Rugby, local em que, em 1823, William Webb Elis inventou o célebre esporte que leva o nome da instituição. Corpo atlético e espírito esportivo sustentavam a concepção de que a prática seria de grande utilidade para educar e formar os jovens das elites que ocupariam os espaços de liderança no Império:

Um alargamento dramático e a transformação da educação secundária privada providenciam a melhor maneira de entender a peculiar importância relacionada à regulação e promoção dos esportes pelas elites vitorianas. Foram os homens das public schools que fundaram, entre outros organismos nacionais, a Football Association, em 1863, a Rugby Union, em 1871, e a Amatheur Athletic Association, em 1881 (Holt, 1989, p.4).

Se inicialmente era compreendido como um privilégio das elites, com o decorrer do tempo, em função das tensões sociais, das distensôes das 
compreensões iniciais e do próprio contexto de construção do ideário e imaginário da modernidade, o esporte, em sua nova estruturação, passa a ser apresentado como uma diversão "apropriada", oferecido como uma alternativa aos antigos jogos populares "condenados". A mesma população que vira perseguida a sua possibilidade de jogar passa a ter o "direito" de acesso ao novo espetáculo, idealmente concebido enquanto consumo passivo, tanto no sentido da prática em si (a maioria somente podia assistir) quanto no de interferência no desenvolvimento do campo que se gestava (poucos tinham a possibilidade de participar da direção de iniciativas e entidades representativas).

Isso, contudo, não significou: a) que as camadas populares abandonaram com facilidade suas práticas tradicionais; b) que ao participar do campo esportivo sistematizado, tais camadas tenham absorvido exatamente os sentidos encaminhados; c) que não tenham interferido e contribuído para reelaboraçóes. O futebol é um exemplo típico de como houve um processo de interferências múltiplas, não lineares.

$\mathrm{O}$ esporte esteve profundamente imbricado com o desenvolvimento de uma cultura de massas, uma sociedade progressivamente marcada pelas ideias de consumo e espetáculo ${ }^{15}$. Entretanto, ao mesmo tempo em que se tornava cada vez mais popular, continuava a ser concebido como um elemento de "status" e distinção.

Um exemplo claro é o turfe, que no decorrer do século XIX deixou de ser exclusivamente aristocrático para ser também burguês, e logo seria popular, em grande parte graças à presença das apostas. Como bem define Holt (1989), "é possivelmente o melhor exemplo de um esporte que permaneceu muito reservado em termos sociais, mas também tendo uma grande e popular assistência” (p.181).

O turfe também é um bom exemplo de transição conceitual. Não por acaso, em muitos países, inclusive no Brasil, esteve entre os primeiros esportes a se organizarem, mais próximo que estava de uma realidade das cidades do início do século XIX, ainda muito marcadas por um caráter rural. Ressalte-se que a princípio ainda não estava definitivamente estabelecida uma relação entre a prática esportiva e o exercício: nas corridas de cavalos, quem faz a atividade física é um animal, não um homem.

Mudanças ocorrem com o aumento das preocupações com o saneamento das cidades e com a saúde da população, em função dos desdobramentos do avanço da industrialização e da rápida urbanização. Era necessário estabelecer novos parâmetros de convivência que permitissem às nações (essa também era uma relativamente nova ideia à época ${ }^{16}$ ) rumarem em "direção ao progresso".
Cada vez mais se fazem sentir necessárias e são entabuladas estratégias de controle corporal e de preparação de um "corpo saudável". Pode-se observar a criação dos métodos ginásticos e o aumento das preocupações com a educação física, já identificáveis na realidade europeia desde a transição dos séculos XVIII e XIX. Certamente isso tem relação com o pronunciado desenvolvimento científico, o aumento das compreensões acerca do funcionamento corporal e o exponenciar da ciência enquanto ditame fundamental no direcionar dos novos rumos sociais ${ }^{17}$.

O esporte, assim, passa a ser concebido como estratégia de formação corpórea; uma boa ferramenta para a preparação de corpos musculosos (que passaram a ser considerados padrões de saúde), bem como para a difusão desse modelo como um ideal a ser perseguido ${ }^{18}$. Um novo "modus vivendi" (um novo conjunto de símbolos e comportamentos, uma nova cultura) estava sendo gestado e a prática esportiva nele se inseria.

Com sua vinculação à saúde (uma relação equivocadamente linear que permanece até os dias de hoje), vários produtos passam a ser vendidos tendo-o como mote: tônicos, fortificantes, xaropes. A publicidade, que no momento também melhor se delineava, não deixou o esporte passar despercebido (Melo, 2008a). Muito rapidamente ao redor da nova prática, dialogando com a própria melhor configuração de uma indústria do lazer e do entretenimento, foram concebidas e implementadas estratégias múltiplas e cada vez mais multifacetadas de negócios. Não surpreende, assim, que tenha sido progressivamente compreendida (e por alguns adotada) como um estilo de vida.

As questões de gênero são notáveis nesse novo cenário. Majoritariamente, o esporte é concebido como uma "escola de masculinidade", uma ferramenta que explicita os novos comportamentos socialmente esperados dos homens. De outro lado, as mulheres nele encontram um excelente argumento para a conquista de maior espaço social, uma forma de reivindicarem a possibilidade de uma maior presença na cena pública ${ }^{19}$.

Enfim, o esporte, nesse processo, constituiu-se em poderosa representação de valores, sensibilidades e desejos que permeiam o ideário e imaginário da modernidade: a necessidade de superação de limites, o extremo de determinadas situações (comuns em um cenário em que a tensão e a violência foram constantes), a valorização da tecnologia, a consolidação de identidades nacionais, a busca de uma emoção controlada, o exaltar de um certo conceito de beleza. O seu desenvolvimento tem grande relação com uma sociedade que enfatizava as noções de produção, precisão, desempenho e disputa: 
Os esportes adotavam e aperfeiçoavam a proeza realizada dentro de padrões precisos e mensuráveis, forneciam a prova do progresso com recordes que sem cessar superavam recordes anteriores: desempenhos em que homens (e, no seu devido tempo, mulheres) mediam suas forças não só um contra o outro, mas também contra a escala impessoal do tempo. Numa era de entretenimento, propunham diversôes espetaculares, primeiro para uns poucos, depois para a maioria (WEBER, 1988, p.281).

Entende-se, assim, por que a prática tenha sido tão fortemente adotada pela burguesia, "esmagadoramente liberal [...] num sentido ideológico, [que] acreditava no capitalismo, empresa privada competitiva, tecnologia, ciência e razão" (HoBSBAWM, 1996, p.341). Bastante ajustada à estrutura de sentimentos da sociedade que se consolidava, logo suas peculiaridades vão extravasar para outros fóruns. Competições passam a ser organizadas por todos os lados, seja enquadrando os antigos costumes em um novo formato, seja por meio de apreensão da sua dinâmica em espaços que a princípio fogem ao esportivo. Um dado curioso é a realização de "olimpíadas" em distintas esferas.

Por exemplo, as Olimpíadas Internacionais de Matemática foram realizadas pela primeira vez em 1959, na Romênia, sendo até hoje anualmente promovidas, envolvendo comumente participantes de mais de 100 países. Podemos identificar eventos semelhantes relacionados à física (realizados desde 1967), à biologia (desde 1990), à química (1968), entre outras (entre as quais filosofia, geografia, filosofia e linguística).

Certamente que aí se destaca mais a ideia de competição do que de diversão. De fato, o próprio campo esportivo, cada vez mais profissionalizado, passa a dividir sua acepção original de divertimento com as noções de trabalho e de negócios.

Talvez possamos mesmo falar de um processo de "esportivização" da sociedade, isso é, a adoção de determinadas características da prática esportiva moderna como pressupostos generalizados. Obviamente que o inverso também é claramente observado: o esporte passa a servir como fórum de dramatização dos conflitos de ordem política, social, econômica, cultural.

É claramente inteligível, dessa maneira, o enorme espaço e popularidade das grandes competições esportivas mundiais. Eventos como a Copa do Mundo de Futebol e os Jogos Olímpicos, que envolvem, como poucos, indivíduos dos mais diferentes países e dos mais distintos perfis, são palcos perfeitos para a manifestação de tensões políticas (de controle ou contestação, sempre como forma de propaganda), para a tematização/ apresentação de questóes culturais e, obviamente, para que estratégias comerciais sejam entabuladas ${ }^{21}$.

Uma imagem. Muitas imagens. A todo momento, a todo instante. Em todos os lugares. Quase uma onipresença. Quase um fenômeno total: é praticamente impossível encontrar algum lugar nesse planeta em que o esporte não esteja presente no cotidiano de milhões de pessoas. Atletas em publicidades e desfiles de modas; fotos nos jornais e nas revistas; matérias na televisão e no rádio; inspiração para o "design" de produtos; jogos nos videogames e computadores; milhares de "sites", "blogs" e "fotologs". Se uma imagem vale mais do que mil palavras, como diz a máxima moderna, sobre o esporte temos então certamente milhões de informações.

\section{Um olhar sobre o(s) conceito(s) moderno(s) de "sport": um modelo heurístico}

No decorrer do século XIX, consolida-se o esporte moderno, que vai adquirindo formatos distintos. Observam-se ajustes conceituais: se há permanências de elementos de momentos anteriores, são claras as mudanças relacionadas às experiências históricas de cada instante (e a rapidez dessas no XIX tem relação com as próprias características da modernidade ${ }^{22}$ ).

Para a construção de um modelo heurístico que nos permitisse uma compreensão global sobre tal desenvolvimento, trabalhamos com a hipótese de que sua estruturação seguiu um conjunto aproximado de transformações, não lineares (não devem ser vistas como uma progressão matemática), não excludentes (isso é, os momentos são cumulativos e mesmo se misturam) e que devem sempre ser prospectadas tendo em conta as diversas realidades em que se inserem (isso é, ainda que haja um vetor principal de influência, em cada espaço/ momento o esporte também desenvolveu peculiaridades; essa talvez seja uma das chaves para entender a sua enorme capacidade de difusão e popularidade: poucos produtos são tão globais e locais simultaneamente).

\section{$1^{\mathbf{0}}$ momento (primeira metade do século XIX)}

Ainda que em grande medida deva-se sua estruturação a uma nova sistematização de antigas 
práticas no âmbito das "public schools" inglesas, o primeiro esporte organizado, no sentido moderno, era marcado pelo uso do cavalo, que estabelecia, na cidade, um elo com a tradição do campo, conectava a nova manifestação cultural com antigos hábitos e "poupava" os homens de maiores exibiçôes corporais, em um momento em que os desdobramentos das ocorrências da modernidade eram embrionários. Tratava-se, portanto, de uma prática ainda mais afeita aos hábitos aristocráticos, uma adequação de alguns antigos costumes a um novo modelo de organização social que dava seus primeiros passos.

$\mathrm{O}$ turfe, esporte por excelência desse primeiro momento, dividia espaço com algumas antigas práticas que seguiam existindo, ainda que com restrições e/ ou passando/prestes a passar por regulamentaçōes: é o caso do pugilismo (sempre cercado de polêmicas) e das atividades com animais, especialmente as brigas (de galo, de cachorro, de urso, entre outros) e touradas, que começavam a passar por um processo de perseguição que iria desembocar em sua proibição, resultado de iniciativas de controle dos costumes das camadas populares, de influência do pensamento puritano e mesmo da mudança no que se refere à sensibilidade para com a violência.

Em vários países do mundo, inclusive no Brasil (como veremos mais à frente), os conceitos de esporte e turfe chegaram a se confundir. WEBER (1988) lembra que na França isso ocorreu com frequência durante muitos anos, sendo mesmo registrado no Dicionário Emile Littré.

Em grande medida, portanto, o "sport" ainda estava bastante relacionado à ideia de diversão "gratuita" (isso é, sem nenhuma indicação moral mais explícita), já mais bem estruturada e gestando um mercado a seu redor, um desdobramento das experiências do século XVIII. A noção de competição já é clara.

\section{$\mathbf{2}^{\mathbf{0}}$ momento (terceiro quartel do séculoXIX)}

A reestruturação de algumas atividades relacionase (como causa e consequência) com a redução de injunçôes de natureza moral no que se refere à exposição corporal pública (ainda que isso tenha significado também a construção de um regime de disciplinamento): cresce a popularidade daquelas práticas nas quais o movimento humano é o elemento central; essas vão, paulatinamente, substituir ou ao menos igualar na preferência, o turfe. Os jogos de azar e o ato de apostar serão combatidos, tidos como velhos costumes que deveriam ser apagados. $\mathrm{O}$ remo é um bom exemplo desse segundo momento.

Os esportes estão mais próximos do que hoje se concebe de forma generalizada: ao seu redor, tornaram-se comuns imagens de desafio, superação, higiene, saúde. Essas dimensões marcam também outras modalidades que melhor se delineiam nesse momento: a natação, o atletismo (ainda dividido em "corridas a pé" e "jogos atléticos") e mesmo as lutas, submetidas a um processo cada vez maior de estabelecimento de regras e de adequação ao que simbolicamente se espera de uma prática moderna. O processo de racionalização é claro, expresso não só na organização de entidades específicas, como também no desenvolvimento de técnicas corporais tendo em vista a obtenção de melhores resultados (que começam a ser mais comumente registrados).

Em instante aproximado, na medida em que a gestação mais clara de uma indústria do entretenimento traz em seu bojo o crescimento de alternativas de uma maior mistura social, inclusive como estratégias de distinção também melhor se sistematizam algumas práticas mais ligadas a um estilo de vida burguês, ou melhor, à nova conformação das elites, estabelecendo pontes entre os diferentes estratos das altas camadas. Nesse cenário, destacam-se o críquete, o croquete, o golfe, o tênis e o iatismo ${ }^{23}$.

Vejamos que essas são modalidades vivenciadas, a princípio, no campo, certamente um novo formato do "rural". Na verdade, nesse momento, inclusive em função do rápido crescimento das cidades (que passaram não poucas vezes a ser vistas como caóticas) e do melhor desenvolvimento do sistema de transporte (onde se destacam as linhas férreas), cresce a procura da natureza para práticas de lazer; desenvolveram-se mesmo esportes específicos relacionados a esse novo hábito (montanhismo, por exemplo).

Uma importante novidade é o início de uma maior presença das mulheres na prática esportiva e do ampliar de seu grau de participação. Como lembra Hobsвawm (1988): "O triunfo do tênis é inconcebível sem a suburbanização e a progressiva emancipação da mulher de classe média" (p.257). Paulatinamente, mais do que como público, passarão a ser aceitas como praticantes, o que de forma alguma significa o abandono da compreensão de que o esporte é uma atividade plenamente adequada para forjar determinados modelos de masculinidade.

Percebem-se, logo, mudanças claras no conceito de "sport": o sentido de diversão permanece forte, mas torna-se mais explícita uma base moral. A ideia de competição seguirá sendo de grande importância, já filtrada por novas lentes, relacionada às noções de produção e trabalho. Curiosamente, e mesmo aparentemente paradoxal, o ideal burguês que marca esse novo formato explicitamente se expressa na 
compreensão de que se tratava de uma prática de amadores, isso é, para aqueles que não necessitam dela para sobreviver, nem estão envolvidos com tarefas laborais manuais; uma forma de distinção social.

\section{$3^{\mathbf{0}}$ momento (último quartel do século XIX)}

Com o esporte completamente imerso no novo contexto sociocultural, marcado pelas ideias de consumo e espetáculo, o próximo fluxo de desenvolvimento esteve compreensivelmente ligado ao uso de artefatos tecnológicos, objetos que representavam a valorização do progresso e da velocidade, marcas dos "novos tempos". Os desafios possíveis ao corpo humano passam a ser pequenos perante as enormes possibilidades que se abrem com o uso de novos aparatos, algo potencializado por um contexto marcado pela busca insaciável por novidades cada vez mais assombrosas. Como exemploschave desse momento, podemos mencionar o ciclismo e, futuramente, o automobilismo e a aviação, práticas que encantaram os seres humanos, celebrando a nova cidade que não cessava de mudar.

Não se pode deixar de comentar a importância da bicicleta, a primeira máquina de transporte individual, uma invenção que, conforme foi sendo aperfeiçoada e tendo seu custo barateado, cada vez mais foi ocupando lugar simbólico como sinal de liberdade e possibilidade de locomoção, especialmente para as mulheres (SCHETino \& Melo, 2009).

Se antes o registro do tempo já era valorizado, essa dimensão se exponencia, até mesmo em função da criação e aperfeiçoamento de instrumentos (entre os quais os cronômetros) que cada vez mais permitiram refinar a mensuração dos resultados, que passam a ser apresentados como sinal de sucesso e meta a ser batida (a valorização do recorde, originário do inglês to record, recordar), expressão de um tempo em que a indústria pesada permitia o exponenciar da produção. Como lembra Vigarello (2001), "o esporte não inventa estes novos cálculos, já amplamente sugeridos pelas locomotivas e pelas novas máquinas. Simplesmente torna-os mais sistemáticos, mais familiares" (p.253).

Considerando que as novas tecnologias ampliaram a estruturação e o alcance da cultura de massa, marcaram a nova excitabilidade pública e geraram novos comportamentos ${ }^{24}$, podemos inferir que a ideia de diversão vai ser potencializada pela noção de espetáculo, tornando mais polêmica e menos sólida a ideia de uma "missão moral", embora essa dimensão jamais vá desaparecer do âmbito dos discursos, mesmo porque se estabelece como um diferencial para a prática, inclusive do ponto de vista comercial.

\section{$4^{\circ}$ momento (transição dos séculos XIXe XX)}

Por fim, os esportes coletivos, a princípio estruturados no âmbito das public schools, vão melhor se delinear (ou serem criados, caso do basquetebol, 1891, e do voleibol, 1895), sair do escopo escolar e se popularizar, o que modificou, uma vez mais, o sentido da prática esportiva. Esse fluxo de desenvolvimento é marcado pelo maior envolvimento de indivíduos das mais diferentes classes sociais, ainda que em espaços específicos nas instalações e majoritariamente, inclusive como praticantes, em determinadas modalidades. Destacam-se o rúgbi e o futebol, este último o esporte que obterá a maior popularidade por todo o mundo.

O futebol foi um dos esportes que mais rapidamente foi apropriado no âmbito da formação de uma cultura operária, tornando-se mais relacionado ao mundo dos "pubs" 25 (onde, aliás, se originaram práticas específicas, como a do bilhar e a dos dardos), à bebida e às apostas, sempre muito apreciadas.

Conceitualmente, observa-se um exponenciar das dimensōes do momento anterior: o caráter de diversão tornar-se mais notável com a massificação da prática, a diversificação de interesses e a lógica comercial cada vez mais empurrarão a dimensão moral para o âmbito dos discursos. O caráter de competição e de superação de resultados se imporá, dialogando claramente tanto com o internacionalismo que marca o segundo momento da Revolução Industrial quanto com as necessidades de construção de identidades nacionais. Pode-se dizer que a nova moral que se gesta de alguma forma se desloca dos indivíduos para os coletivos.

Nesse cenário, paulatinamente a ideia de que se trata de uma prática de amadores será substituída pela de profissionalização: de atletas, dirigentes e de muitos outros profissionais que progressivamente atuarão no campo, um claro processo de especialização.

\section{$5^{\circ}$ momento (transição dos séculos XXeXXI)}

No decorrer do século XX, surgiram muitas modalidades esportivas; em geral, pode-se percebê-las como desdobramentos dos momentos anteriormente descritos. Há, todavia, uma nova configuração em pleno desenvolvimento. Com o aperfeiçoamento das ferramentas computacionais, fazer esporte nem sempre significa mover o seu corpo, mas sim jogar com simulações, situações ideais criadas nas telas.

Como se pode ver na página do projeto Esporte e Arte $^{26}$, desde o tempo do Telejogo, primeira geração de "games", são muitos os jogos eletrônicos que fazem 
da prática esportiva o motivo central. Aliás, com o Wii, vemos a junção entre o movimento corporal e o que ocorre no monitor, uma nova forma de interação ${ }^{27}$.

Alguns mais desconfiados podem afirmar que isso não é esporte. Quero lembrar que nem sempre a movimentação corporal foi parte essencial do fenômeno esportivo, como vimos no que se refere ao primeiro e mesmo ao terceiro momentos. Além disso, enquanto prática social que deve ser historicizada, não podemos nos prender a apreensões essenciais: o esporte é aquilo que em cada momento se defina como tal, conceitos relacionados a experiências históricas específicas.

Vale ainda lembrar o sucesso de alguns jogos eletrônicos esportivos, principalmente do FIFA Soccer. Aliás, a entidade máxima do futebol já premia anualmente, junto com os craques de outras categorias (masculino, feminino, futsal, praia), o melhor jogador do game. Em certa medida, processo semelhante já ocorrera anteriormente com outras atividades ligadas ao "velho esporte bretão", caso, por exemplo, do futebol de mesa (nome oficial do esporte também conhecido no Brasil como futebol de botão ou jogo de botão) ${ }^{28}$.

Precisamos de mais investigações para melhor compreender as mudanças conceituais que estão a se configurar nessa nova dinâmica (na verdade, esses estudos já estão em marcha no nosso país e por todo o mundo). Supõe-se que tenham ligação com as peculiaridades da cibercultura, especialmente o rompimento com as relaçôes tradicionais de tempoespaço físicos. A questão fundamental é: se mudou a forma de relação com o outro, de relação com o corpo, de representação do corpo, por que não mudaria a concepção do que significa fazer esporte?

\section{Considerações finais: aplicando o modelo ao caso do Rio de Janeiro}

Para concluir esse artigo, pareceu-nos interessante aplicar o modelo proposto a um caso brasileiro. Apresentamos, então, algumas compreensões iniciais e resumidas sobre o Rio de Janeiro, capital do país no século XIX, sua cidade mais importante naquele momento. Nesse município se sentiram especialmente os impactos da modernidade, o que ajuda a explicar o fato de ter sido pioneira na estruturação do fenômeno esportivo no país.

Luiz EDMUNDO, notório memorialista do Rio de Janeiro, afirma que as primeiras manifestações esportivas surgiram na cidade no final do século XIX: "Até o fim do século que passou nós vivíamos, a bem dizer, indiferentes aos prazeres e às alegrias salutares do esporte" (1957, p.831).

$\mathrm{O}$ autor está, na verdade, apresentando sua percepção sobre o aumento da presença do esporte no contexto cultural carioca, a partir de uma concepção contemporânea, na qual fica clara uma relação com o grau de solicitação física requerida pela atividade.

$\mathrm{Na}$ verdade, não só o esporte moderno, como a utilização do termo "sport", é bem anterior ao que supõe Edmundo. Desde o segundo quartel do século XIX podemos identificar o uso corrente da palavra nos periódicos cariocas: em um país que pretendia modernizar-se, chegavam as primeiras informaçōes sobre a prática (por jornais e/ou revistas importados, por brasileiros que na Europa moraram ou pelos estrangeiros que se estabeleceram na cidade) e as pioneiras experiências começaram a ser organizadas.
Por aqui também, nos primeiros momentos, eram consideradas "sport" diversas práticas relacionadas à diversão. Algumas dessas, que obtiveram na época algum sucesso, hoje são vistas com curiosidade e humor. Por exemplo, as corridas de cachorro e as corridas de pombo-correio. Outras foram proibidas com o decorrer do tempo (já no século XX), um processo semelhante ao que ocorrera na Inglaterra; esse é o caso das brigas de galo e das touradas ${ }^{29}$. Podemos identificar ainda algumas atividades que existem até hoje sem serem consideradas esportivas, como os banhos de mar, o jogo do bicho (mesmo que proibido por lei) e a patinação não competitiva.

O esporte moderno começa a se organizar no Brasil nos anos finais da primeira metade do século XIX, com a criação de um clube de turfe (Club de Corridas, 1849), embora anteriormente já tenham sido organizadas algumas esporádicas corridas de cavalos. Dois foram os principais argumentos que estiveram nos discursos dos responsáveis pela criação dessa e de outras agremiações pioneiras: o desenvolvimento de uma diversão em uma cidade "carente" dessas possibilidades e o aperfeiçoamento da "raça cavalar" brasileira (MELo, 2001).

Depois de um período inicial de dificuldades, a partir dos anos 1860 o turfe torna-se mais organizado e progressivamente ganha espaço no Rio de Janeiro, resultado inclusive do processo de urbanização e do desenvolvimento de um sistema 
de transportes. A popularidade já era bastante pronunciada nos anos 1870 .

A presença dos cavalos conectava o desejo de uma cidade que pretendia se modernizar com uma realidade ainda bastante rural. $\mathrm{O}$ discurso moral ainda não era o prioritário; o turfe ainda não era encarado como um esporte segundo as compreensões que comumente tendemos a considerar. Estava longe de ser uma prática que solicitasse grande movimentação física, não havia ainda uma relação direta com a saúde e com a estética. De fato, durante muitos anos o exercício físico foi rechaçado e considerado prejudicial por parte significativa da sociedade, principalmente pelas elites. Tanto que o jóquei, responsável pela condução dos cavalos, era normalmente escolhido entre as camadas populares. O "sport" ainda era encarado mais como um jogo e uma diversão "gratuita" (embora já encarado como sinal de "status" e distinção e oportunidade de negócios pelos membros da elite econômica) ${ }^{30}$.

Conduzido pelas elites ligadas à economia agrícola cafeeira, o turfe desenvolveu-se muito em um período de relativo sucesso financeiro do país. Nesse contexto, os jogos com apostas passaram a ser um sucesso, o que contribuiu para que estivesse entre as práticas mais populares do momento. Situamos, então, esses primeiros instantes dentro do que denominamos de " 10 momento" em nosso modelo heurístico.

A partir do quartel final do século XIX, a economia começa a se diversificar. Percebe-se a organização e ascensão de um novo setor das elites, com características urbanas, formado por industriais, comerciantes e intelectuais de origem nacional. Esses vão colocar em questionamento o próprio ethos da elite agrícola.

Os setores urbanos ganham um maior poder com a abolição da escravatura, em 1888, e com a proclamação da República, em 1889. Influenciados pelo positivismo, pretendiam "modernizar definitivamente" o país. $\mathrm{Na}$ verdade, o que se observou não foi uma cisão, mas uma acomodação entre os diversos setores. Atenderam-se aos interesses tanto do capital agrário quanto do urbano. Ajustaram-se continuidade e mudança. O Rio de Janeiro passou a viver e ser o exemplo claro da tensão entre dois pólos: a realidade colonial e o desejo de implementar o dinamismo das metrópoles.

Nesse contexto, emergiram muitas críticas às corridas de cavalos, por lembrar algo ultrapassado, ligado à monarquia, ao rural. Se essas não foram suficientes para eliminar a prática, os clubes de turfe viram sua popularidade se reduzir bastante no final do século XIX e no decorrer do século XX, até mesmo porque novos esportes e novas diversões se desenvolveram.
Se o turfe influenciou decisivamente os outros esportes (que utilizaram como modelo sua estrutura e forma de organização, até mesmo sua linguagem específica), as compreensões ao redor do que significava e deveria significar a prática esportiva se modificariam principalmente a partir (e em consequência) do desenvolvimento do remo. No final do século XIX, o remo ganhou espaço e prestígio na cidade, inserido no quadro de modificaçôes socioculturais em curso. Para a ocupação das praias, do mar, e principalmente para o desenvolvimento do esporte náutico, foram fundamentais o delineamento de uma cultura urbana, o enaltecimento de padrōes saudáveis de vida, a aceitação de exibição de um corpo belo e forte, a difusão do "pensamento científico", a emergência e valorização do lazer, a busca de novas formas de sociabilidade.

O remo contribuiu de forma fundamental para estabelecer e estabilizar valores que de alguma forma até hoje permanecem ao redor da prática esportiva: a valorização do desafio; a ligação com a atividade física, tão importante para a manutenção da saúde e para a consolidação de uma nova estética corpórea, na qual a beleza diretamente ligada à compleição muscular era valorizada; a suposta honestidade e probidade moral dos que com o esporte se envolvessem; uma suposta "escola de virtudes". As apostas foram eliminadas. Tratava-se de um novo estilo de vida.

O remo era, assim, apresentado como o esporte mais adequado aos "novos tempos", estando ligado aos desejos das elites de recriar um mundo europeu no Brasil ${ }^{31}$. Aqui situamos, portanto, o que chamamos no nosso modelo heurístico de "20 momento".

$\mathrm{Na}$ transição dos séculos XIX e XX, outros esportes já estavam em plena organização na cidade ${ }^{32}$. A natação, por exemplo, cujas primeiras iniciativas estiveram relacionadas às preocupações com a segurança dos banhos de mar e da prática do remo, já era concebida como estratégia para a manutenção da saúde.

Já o atletismo (corridas a pé e jogos atléticos) tem uma trajetória curiosa. De início, se tratava quase de uma brincadeira organizada pelos ingleses que viviam no Rio de Janeiro ${ }^{33}$. Tanto assim que o programa era dos mais curiosos, notadamente nas provas de corridas, que previam categorias com o uso de sacos de estopa ou pernas de pau.

O que ocorre é que a prática caiu no gosto popular, notadamente as corridas a pé, e muitos clubes específicos foram criados. O problema é que parte dessa popularidade se devia às apostas, e o atletismo teve que passar por um processo de adequação aos novos olhares sobre o esporte: a eliminação do 
caráter de jogo de azar e a vinculação aos discursos de saúde e higiene.

Esse foi também, aliás, o caso do ciclismo: a população era atraída pelas apostas, e a prática se tornou uma febre na virada dos séculos. Os velódromos chegaram a ser fechados, sendo somente reabertos quando os dirigentes dos clubes se comprometeram a coibir o caráter de jogo de azar, afirmando que as corridas de bicicletas deviam ser entendidas como um esporte que poderia trazer contribuiçōes à juventude brasileira ${ }^{34}$.

Algumas modalidades, por mais que tentassem se ajustar à nova dinâmica sociocultural e às novas representaçôes de esporte, permaneceram "suspeitas", ainda que nunca tenham sido efetivamente proibidas, caso da luta romana e do boxe. Há ainda o curioso caso do jogo de pelotas: mesmo que seus dirigentes tenham adaptado o discurso, não conseguiu lograr continuidade e acabou proibida ${ }^{35}$.

Vale ainda algumas palavras sobre o automobilismo, pelo seu simbolismo na construção do ideário e imaginário da modernidade, o esporte que, junto com o ciclismo, marca o que chamamos de " 3 o momento" no modelo heurístico. Encarado como substituto e superação da natureza (de cavalos e da força humana), o automóvel é uma marca da chamada Segunda Revolução Industrial e um dos símbolos mais importantes do século XX. O automobilismo, em grande medida, é entendido como o exponencial dessa representação simbólica.

É largamente aceito que o primeiro automóvel tenha chegado ao Brasil pelas mãos de Alberto Santos Dumont, em São Paulo (1892); no Rio de Janeiro, desembarcou alguns anos depois, em 1895, importado por José do Patrocínio, líder abolicionista e importante personagem da política nacional.

Os primeiros proprietários brasileiros de automóveis eram membros das elites, que gozavam de algum sucesso financeiro no momento e que, mesmo quando originários de famílias tradicionais, possuíam, em maior ou menor grau, relação com o projeto de modernização do país. O uso do veículo estava relacionado inicialmente mais à busca de elementos de "status" e distinção, uma forma de vinculação ao "civilizado mundo moderno", do que a interesses econômicos. Precedidas dos desafios de longos percursos, no início do século XX realizam-se as primeiras corridas, inicialmente em São Paulo, depois no Rio de Janeiro ${ }^{36}$.
Além desses, nos primeiros anos do século XX já estavam em processo de organização o pólo aquático, $\mathrm{o}$ tênis, o iatismo. Também já estavam estruturados alguns esportes que permaneceram bastante circunscritos ao âmbito das elites, encarados como sinais de "status" e distinção e ferramentas de educação elevada, caso da esgrima, do hipismo e do tiro ao alvo ${ }^{37}$.

De outro lado, um esporte da maior importância dava os primeiros passos: o futebol. Como afirma João do Rio: "[...] o Rio compreendeu definitivamente a necessidade dos exercícios, e o entusiasmo pelo futebol, pelo tênis, por todos os outros jogos, sem diminuir o da natação e das regatas - é o único entusiasmo latente do carioca [...] Não! Há de fato uma coisa séria para o carioca: - o futebol!" (citado por CosTA, 1961, p.279).

A chegada do velho esporte bretão modificaria uma vez mais os sentidos da prática esportiva: tornar-se-ia ainda mais popular e paulatinamente, não sem tensões, mais acessível para os que desejam praticar e não só assistir. Chegamos ao " 4 " momento”, segundo a tipologia do modelo heurístico.

Ao apresentar o desenvolvimento esportivo do Rio de Janeiro, não o estamos fazendo por considerá-lo um padrão. Ao contrário, tendo o modelo heurístico em conta, ao demonstrar que é possível aplicá-lo ao caso carioca, estamos supondo que pode ser útil fazer o mesmo com outras cidades brasileiras, cujas diferenças não podem ser negligenciadas e têm sido pouco investigadas.

Ao entabular tais esforços, teríamos parâmetros de comparação entre as diversas localidades (o próprio modelo), sem a necessidade de que uma delas seja considerada como padrão. Com isso, poderíamos melhor perceber regularidades e peculiaridades, semelhanças e diferenças; caminharíamos para buscar uma síntese histórica mais aprofundada. Na mesma medida, teríamos mais condiçōes de fazer dialogar o caso nacional com o cenário internacional, percebendo o que há de específico na experiência esportiva brasileira.

Parecem alvissareiras, assim, as perspectivas que se abrem. De qualquer forma, a utilidade do modelo heurístico só será melhor demonstrada com sua utilização em outras investigações, o que inclusive pode contribuir para seu aperfeiçoamento. 


\begin{abstract}
Notes to a comparative history of sport: a heuristic model

Considering the recent growth of historical research that has as object the institutionalized body practices, Meıo (2007a), even though recognizes the importance of these efforts, demonstrates concern about the fragmentation of these initiatives. To this author, a possible solution would be the use of the method of Comparative History, a contribution to search for deep historical analyzes. Since these understandings, this article aims to present a heuristic model whose aim is to establish itself as a tool to analyze/interpret the sport modern conceptual trajectory. Built primarily from the history of the sport, we believe that it can be a useful tool not only for the development of local studies, but also to comparative investigations.
\end{abstract}

UNITERMS: History of sport; Sociology of sport; Methodology of history.

\title{
Notas
}

1. A "história das práticas corporais institucionalizadas" abarcaria, em um mesmo campo de investigação, sem excluir outras possibilidades de diálogos, práticas sociais como o esporte, a capoeira, a dança, a ginástica, a educação física (entendida enquanto uma disciplina escolar e como uma área de conhecimento), atividades específicas de períodos anteriores à Era Moderna (da Antiguidade e da Idade Média), entre outras (Melo, 2007a).

2. Como qualquer modelo heurístico, esse se baseia mais na intuição e na análise de circunstâncias, buscando auxiliar no processo de novas descobertas, visando a gerar novas interpretações. Embora também parta, mesmo que não explicitamente, de dados empíricos, guarda um nível de abstração.

3. Francês antigo comumente designa variantes da língua românica falada, entre os séculos XI e XIII, em área que hoje corresponde a algumas regiōes da França, Bélgica e Suíça.

4. Vale lembrar que, até hoje, o verbo "to play" (que surge no século XIV como "oposição ao trabalho") pode ser utilizado para designar uma encenação, uma performance musical ou a prática de jogos e esportes.

5. Para uma discussão sobre tal configuração na Inglaterra do século XVIII, ver estudo de SOARES (2007).

6. Para mais informações, ver estudo de Holt (1989) e Melo (2009b).

7. Para uma discussão sobre a popularidade dessas práticas, ver Holt (1989).

8. Tal obra, sem maiores especificações, está disponível em: http://www.oxforddnb.com/public/hogarth/.

9. Gravura, 1735, 35,5 x 40,5 cm. Acervo do British Museum/Londres. Disponível em: http://www.britishmuseum.org.

10. À época havia um grande número de watermen trabalhando no Tâmisa, responsáveis pelo transporte de mercadorias e pessoal entre as margens.

11. É relevante citar que Doggett era membro do Whig Party, defensor da monarquia constitucional.

12. Para mais informaçôes, ver Bourdieu (1983).

13. Escolas tradicionalmente destinadas a formar os jovens de famílias de classes médias.

14. Vigarello e Holt (2008) lembram que anteriormente já existia uma antiga tradição de organização de jogos em escolas inglesas; o que mudou foi o sentido e a intencionalidade da prática.

15. Para uma discussão sobre essa dimensão da modernidade, ver Charney e SChWARTZ (2001) e Clark (2004). Sobre a presença do esporte nesse cenário, ver MeLo (2006).

16. Para mais informaçōes sobre a ideia de nação, ver НовSBAWм (1988).

17. Para uma discussão sobre a influência dos médicos nesse cenário, ver Melo (2006).

18. No próximo item veremos que argumento que, a despeito desses discursos, o fator primordial de desenvolvimento esportivo foi mesmo sua inserção na lógica da sociedade do espetáculo.

19. Para mais informações, ver Melo (2007b).

20. Devemos lembrar que na Grécia Antiga, olimpíadas era o período de quatro anos entre dois Jogos Olímpicos e não o evento em si, como hoje é muitas vezes considerado.

21. Como indicador do poder e penetrabilidade da prática esportiva, basta lembrar que há mais associados à Federação Internacional de Futebol Association (FIFA) e ao Comitê Olímpico Internacional (COI) do que à Organização das Nações Unidas (ONU).

118 • Rev. bras. Educ. Fís. Esporte, São Paulo, v.24, n.1, p.107-20, jan./mar. 2010 
22. Afirma KoselLECK: "Desde então o encurtamento dos prazos que ainda permitem uma experiência homogênea, ou a aceleração das mudanças, que consome as experiências, passou a fazer parte dos topoi que caracterizam a história mais recente" (2006, p.289).

23. Devemos lembrar que algumas dessas modalidades tinham uma história anterior, sendo por vezes também práticas populares.

24. Lembremos que a luz elétrica e o trem, por exemplo, potencializaram as vivências de lazer; a primeira por ampliar as alternativas de atividades noturnas, o segundo por facilitar as viagens e o acesso a novas localidades. Vale ainda destacar que o avanço tecnológico gerou diretamente novos produtos de lazer como o fonógrafo e o cinema (mais tarde o rádio e a televisão, entre outros).

25.Para mais informações, ver estudo de Новьвашм (2000).

26. http://www.anima.eefd.ufrj.br/esportearte/consulta/home.asp.

27. Wii é um videogame de sétima geração produzido pela Nintendo. Sua principal característica é o controlador sem fios que possui um dispositivo que detecta os movimentos em três dimensôes. Com princípio semelhante, acaba de ser lançado o Zeebo, da Tectoy.

28. A prática é reconhecida como esporte desde 1988, sendo dirigida pela Confederação Brasileira de Futebol de Mesa. É praticado em três modalidades oficiais (Disco, Bola 12 Toques, Bola 3 Toques) e duas experimentais (Dadinho 9x 3 e Pastilha). Para algumas informaçōes históricas sobre o jogo, ver http://www.futeboldemesanews.com.br/default.asp?acao=historia.

29. Para mais informações sobre essas práticas, ver estudo de Melo (2008c).

30. Para mais informações sobre o turfe, ver estudo de Melo (2001).

31. Para mais informaçôes sobre o remo, ver estudo de MeLo (2001).

32. Aqui apresentaremos um resumo. Para mais informaçôes, ver MeLo (2009c).

33. Os britânicos também estiveram envolvidos com a organização das primeiras corridas de cavalos e das pioneiras regatas (Melo, 2001).

34. Para mais informaçóes sobre o ciclismo, ver estudo de Schetino (2008) e Schetino e Melo (2009).

35. Para mais informações, ver Melo (2008c).

36. Para mais informações sobre os primeiros momentos do automobilismo no Brasil, ver estudos de Melo (2008b, 2009a).

37. Para uma discussão sobre as três práticas, ver MELo (2007b).

\section{Referências}

BOURDIEU, P. Como é possível ser esportivo? In: Questóes de sociologia. Rio de Janeiro: Marco Zero, 1983. p.136-63. CHARNEY, L.; SCHWARTZ, V. (Orgs.). O cinema e a invenção da vida moderna. São Paulo: Cosac e Naify, 2001. CLARK, T.J. A pintura da vida moderna. São Paulo: Companhia das Letras, 2004.

EDMUNDO, L. O Rio de Janeiro do meu tempo. Rio de Janeiro: Conquista, 1957.

HOBSBAWM, E. A era dos impérios: 1875-1914. 9. ed. São Paulo: Paz e Terra, 1988. A era do capital: 1848-1875. 11. ed. São Paulo: Paz e Terra, 1996.

Mundos do trabalho. São Paulo: Paz e Terra, 2000.

HOLT, R. Sport and the British: a modern history. New York: Oxford University Press, 1989.

KOSELLECK, R. Futuro passado. Rio de Janeiro: Contraponto/Editora PUC-Rio, 2006.

MELO, V.A. Cidade sportiva: primórdios do esporte no Rio de Janeiro. Rio de Janeiro: Relume Dumará/FAPERJ, 2001. Cinema e esporte: diálogos. Rio de Janeiro: Aeroplano/FAPERJ, 2006.

. Por uma história comparada do esporte: possibilidades, potencialidades e limites. In: MELO, V.A. (Org.). História comparada do esporte. Rio de Janeiro: Shape, 2007a. p.13-32.

Mulheres em movimento: a presença feminina nos primórdios do esporte na cidade do Rio de Janeiro (século XIX-primeira década do século XX). Revista Brasileira de História, São Paulo, v.27, n.54, p.127-52, 2007b. Disponível em: <http://www.scielo.br/pdf/rbh/v27n54/a08v2754.pdf>. Acesso em: 10 maio 2009.

Esporte, propaganda e publicidade no Rio de Janeiro da transição dos séculos XIX e XX. Revista Brasileira de Ciências do Esporte, Campinas, v.29, n.3, p.25-40, 2008a.

. O automóvel, o automobilismo e a modernidade no Brasil (1891-1908). Revista Brasileira de Ciências do Esporte, Campinas, v.30, n.1, p.187-203, 2008b. Disponível em: <http://www.rbceonline.org.br/revista/index.php/RBCE/ article/viewArticle/199>. Acesso em: 16 jun. 2009. 
O que é "sport"? Tensões na definição do campo esportivo na cidade do Rio de Janeiro do século XIX. Revista do Instituto Histórico e Geográfico Brasileiro, Rio de Janeiro, v.169, n.439, p.9-36. 2008c.

Antes de Fittipaldi, Piquet e Senna: o automobilismo no Brasil (1908-1954). Motriz, Rio Claro, v.15, n.1, p.10415, 2009a. Disponível em: <http://cecemca.rc.unesp.br/ojs/index.php>. Acesso em: 10 jun.2009.

Esporte, lazer e artes plásticas: diálogos. Rio de Janeiro: Apicuri/FAPERJ, 2009b.

. Corpos, bicicletas e automóveis: outros esportes na transição dos séculos XIX e XX. In: PRIORE, M.; MELO, V.A. (Orgs.). História do esporte: do Império aos dias atuais. São Paulo: Editora da UNESP, 2009c.

PORTER, R. Os ingleses e o lazer. In: CORBIN, A. (Org.). História dos tempos livres. Lisboa: Teorema, 2001. p.19-58. SCHETINO, A. Pedalando na modernidade. Rio de Janeiro: Apicuri, 2008.

SCHETINO, A.; MELO, V.A. A bicicleta, o ciclismo e as mulheres na transição dos séculos XIX e XX. Estudos Feministas, Florianópolis, v.17, n.1, p.111-34, 2009.

SOARES, L.C. A Albion revisitada. Rio de Janeiro: 7 Letras/FAPERJ, 2007.

VIGARELLO, G. O tempo do desporto. In: CORBIN, A. (Org.). História dos tempos livres. Lisboa: Teorema, 2001. p.229-62. . Exercitar-se, jogar. In: VIGARELLO, G.(Org.). História do corpo. Rio de Janeiro: Vozes, 2008. v.1, p.303-400.

VIGARELLO, G.; HOLT, R. O corpo trabalhado: ginastas e esportistas no século XIX. In: CORBIN, A. (Org.). História do corpo. Rio de Janeiro: Vozes, 2008. v.2, p.393-478.

WEBER, E. França fin de siècle. São Paulo: Companhia das Letras, 1988.

WELSCH, W. Esporte: visto esteticamente e mesmo como arte? In: ROSENFIELD, D. (Org.). Ética e estética. Rio de Janeiro: Jorge Zahar, 2001. p.142-65.

ENDEREÇO

Victor Andrade de Melo R. Silveira Martins, 76 - casa 16 - Flamengo 22221-OOo - Rio de Janeiro - RJ - BRASIL e-mail: victor.a.melo@uol.com.br
Recebido para publicação: 03/08/2009

Revisado em: 08/09/2009

Aceito: 23/09/2009 